\title{
New Solid Catalysts for Clean Technology
}

\author{
Keith Smith · John Meurig Thomas
}

Published online: 27 May 2009

(C) Springer Science+Business Media, LLC 2009

This is not the first time that an issue of Topics in Catalysis has dealt with clean technology or with new solid catalysts. It is obvious, given the likely central importance of each, that it will not be the last. It is almost a platitude to allude these days to the growing importance of clean technology (or of green chemistry). The entire world is aware of it. But even expert scientists are not fully aware of the progress made in devising new solid catalysts or in adapting old ones for unusual purposes. Other things being equal, solid (heterogeneous) catalysts are more convenient to use than homogeneous ones. This issue deals with a variety of distinct topics, all of which, we believe, will inform practitioners in catalysis (and hopefully stimulate others to formulate new ideas and initiatives).

K. Smith $(\square)$

Cardiff, UK

e-mail: smithk13@cardiff.ac.uk

J. M. Thomas

Cambridge, UK

e-mail: jmt2@cam.ac.uk 